\title{
Seismic Analysis of Cylindrical Liquid Storage Tank
}

\author{
Rupachandra J. Aware ${ }^{1}$, Dr. Vageesha S. Mathada ${ }^{2}$ \\ ${ }^{1}$ Shri Vitthal Education \& Research Institute College of Engineering, Pandharpur \\ ${ }^{2}$ Guide, Shri Vitthal Education \& Research Institute College of Engineering, Pandharpur
}

\begin{abstract}
Liquid storage tanks are used in industries for storing chemicals, petroleum products, and for storing water in public water distribution systems. Behaviour of Cylindrical liquid storage tanks under earthquake loads has been studied as per Draft code Part II of IS 1893:2002. A FEM based computer software (STAAD -PRO) used for seismic analysis of tanks which gives the earthquake induced forces on tank systems. Draft code Part II of IS 1893:2002 which will contain provisions for all types of liquid storage tanks. Under earthquake loads, a complicated pattern of stresses is generated in the tanks. Poorly designed tanks have leaked, buckled or even collapsed during earthquakes. Common modes of failure are wall buckling, sloshing damage to roof, inlet/outlet pipe breaks and implosion due to rapid loss of contents. In this research, a circular cylindrical elevated water tank, with 500 cubic meters capacity is analysed by using finite modelling techniques. This paper presents the study of seismic performance of the elevated water tanks for various heights and various seismic zones of India. The effect of height of water tank, earthquake zones on earthquake forces have been presented in this paper with the help of analysis of 20 models for same parameters. Analysis is carried out by using finite element software STAAD-PRO.
\end{abstract}

Keywords: Elevated Circular Cylindrical Tank, Damages, Frame type staging, base Shear, Finite Element Software (STAAD-PRO).

\section{Introduction}

Elevated tank structures are normally used to store water for domestic activities and also fire fighting purposes. Their safety performance is a critical concern during strong earthquakes. The failure of these structures may cause serious hazards for citizens due to the shortage of water or difficulty in putting out fires during earthquakes. Some elevated tanks have shown insufficient seismic resistance in past earthquakes which had prevented the fire fighting process and other emergency response efforts (Barton and Parker, 1987). There have been several studies in which the dynamic behaviour of liquid storage tanks have been analyzed, however most of them have focused on ground level cylindrical tanks, and very few of them have concentrated upon behaviour of elevated tanks. They are heavy structures which a greater portion of their weight is concentrated at an elevation much about the base. Critical parts of the system are columns and braces through which the loads are transmitted to the foundation. Due to the high sensitivity of elevated water tanks to earthquake characteristics such as frequency contents, peak ground acceleration and effective duration of the earthquake records, it seems necessary to ponder the earthquake loading as a non-stationary random pattern.

\section{Earthquake Damage to Liquid Storage Tanks}

There are frequent reports regarding the damage to liquid storage tanks due to previous earthquakes in the literature. For instance, there were heavy damages to both concrete and steel storage tanks during the strong seismic events such as 1933 Long Beach, 1952 Kern County, 1964 Alaska, 1964 Niigata, 1966 Parkfield, 1971 San Fernando, 1978 Miyagi prefecture, 1979 Imperial County, 1983 Coalinga, 1994 Northridge, and 1999 Kocaeli earthquakes (Rinne (1967),
Shibata (1974), Kono (1980), Manos and Clough (1985), and Sezen and Whittaker (2006)).

Severe damage levels were also observed in elevated water tanks during the 1960 Chilean as well as the 1997 Jabalpur and 2001 Bhuj earthquakes in India. During the Bhuj earthquake many elevated tanks suffered severe damages in terms of flexural cracks in the circumferential direction in their supporting shafts near the base. Three elevated water tanks located in the highest intensity shaking zones also collapsed. Heavy damages to cylindrical buried concrete tanks were observed in 1995 Kobe earthquake. An underground concrete tank was also damaged severely in the form of the collapse of the wall during the 1971 San Fernando earthquake (Jennings (1971)).

Failure mechanism of liquid storage tanks depends on different parameters such as construction material, tank configuration, tank type, and supporting mechanism. Reported damage to liquid containing structures (LCS) during past earthquakes fall into one or more of the following categories:

1) Buckling of the shell caused by excessive axial compression of the shell structure due to exerted overturning moment (elephant-foot buckling)

2) Deformation, cracks and leakage in side shell

3) Damage to the roof or the upper shell of the tank, due to sloshing of the upper portion of the contained liquid in tanks with insufficient free board provided between the liquid free surface and the roof

4) Spillover of the stored liquid

5) Failure of piping and other accessories connected to the tank because of the relative movement of the flexible shell

6) Damage to the supporting structure in elevated water tanks

7) Damage to the anchor bolts and the foundation system

8) Failure of supporting soil due to over-stressing 


\section{International Journal of Science and Research (IJSR) \\ ISSN (Online): 2319-7064}

Index Copernicus Value (2013): 6.14 | Impact Factor (2014): 5.611

In the 1964 Niigata earthquake, several damage modes including damage modes 3 and 4 due to excessive sloshing, mode 8 due to liquefaction of the supporting soil as well as damage modes 7 and 5 became prominent.

In the 1964 Alaska and 1971 San Fernando earthquakes, the lower part of the side shell bulged all along the perimeter as a result of mode 1 (elephant-foot buckling). This buckling type damage generally happens due to the excessive overturning moment generated during the seismic event.

In cases where the tank contains hazardous materials, liquid spill over (damage mode 4) and fire subsequent to a major earthquake may result in even more severe damage than the earthquake itself. The extensive uncontrolled fire eruption during the Niigata earthquake at Showa Petroleum blazed for about 15 days, resulting in main destruction of the plant and residential apartments (Niigata Nippo Co. (1964)). The Niigata and Alaska earthquakes of 1964 resulted in considerable loss in the petroleum storage tanks. This significant loss attracted many practicing engineers and researchers to further investigate the seismic behaviour of liquid storage tanks especially when the stored liquid is a hazardous material such as petroleum.

As an example of damage mode 4, one can mention oil spill over into the harbour that happened in the Sendai Refinery of Tohoku Petroleum Company during the 1978 Miyagi earthquake (Hazardous Material Technology Standards Committee: Fire Defence Agency (1979)).

During the Northridge earthquake main lifeline facilities of the Los Angeles area experienced severe damage. Five steel tanks were also damaged in the San Fernando Valley area. Buckling was the prominent form of damage in all of the damaged tanks. Several other tanks also suffered roof collapse due to the excessive sloshing of the stored liquid (Lund (1996)).

It is important to note that the damage mode in concrete tanks is different from that of steel tanks. Elephant-foot buckling, anchorage system failure, and sloshing damage to the roof and upper shell of the tank are the most common damages in steel tanks (see Figure).

In tanks found in practice, full base anchorage is not always a possible or economical alternative. Therefore, many tanks are either unanchored or partially anchored at their base. If the tank is not rigidly anchored to the ground, the generated overturning moment due to earthquake may be large enough to result in lift-off of the tank base. As the tank base falls back down after lift-off, high compressive stresses are generated in the wall near the base leading to elephant-foot wall buckling. This mode of damage is more common in steel tanks since they are generally more flexible than concrete tanks.

Some studies show that base lift-off in tanks having flexible soil foundations does not cause high axial compressive stresses in the tank wall. As a result, unanchored tanks flexibly supported at their base are less susceptible to elephant-foot buckling mode, but are more susceptible to uneven settlement of the foundation (Malhotra (1995) and Malhotra (1997A)).

On the other hand, damage mode 2 is the most common type of damage in concrete tanks. Stresses caused by large hydrodynamic pressures together with the additional stresses resulted from the large inertial mass of concrete could cause cracking, leakage and ultimately failure of the tank. That is why the design criteria for concrete tanks are based on crack control.

It is worth noting that elevated water tanks are very susceptible to seismic excitations because of the concentrated large mass located at top of the shaft structure. As a result, strong lateral seismic motions may result in large tensile stresses on one side of the concrete shaft section which may eventually lead to severe cracking or even collapse of the concrete pedestal.

As mentioned before, many elevated tanks collapsed during the 1960 Chilean, 1997 Jabalpur and 2001 Bhuj earthquakes since insufficient reinforcement was provided in the shaft section

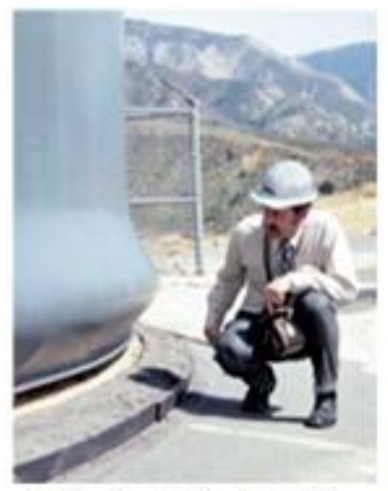

a) Elephant-foot buckling

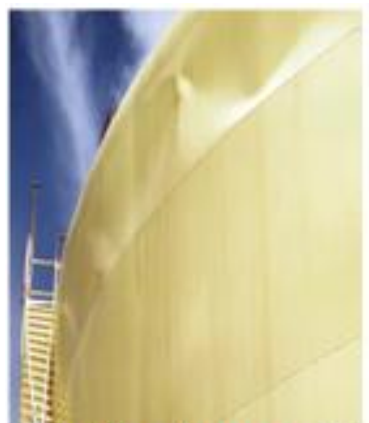

c) Sloshing damage to the upper shell of the tank

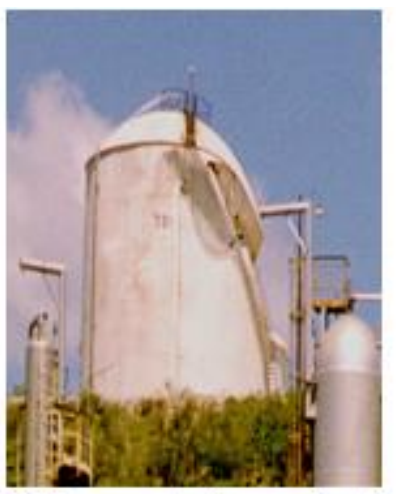

b) Damage to the roof or the Upper shell of the tank

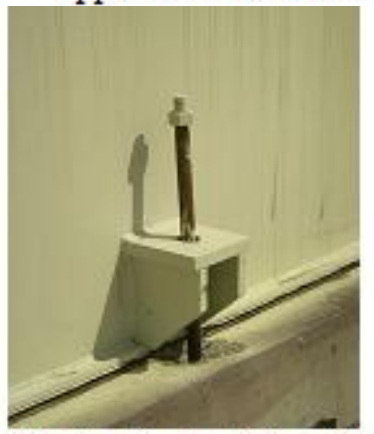

d) Inelastic stretching of an anchor bolt at the tank base

\section{Spring Mass Model For Elevated Tank}

When a tank containing liquid with a free surface is subjected to horizontal earthquake ground motion, tank wall and liquid are subjected to horizontal acceleration. The liquid in the lower region of tank behaves like a mass that is rigidly connected to tank wall. This mass is termed as impulsive liquid mass which accelerates along with the wall and induces impulsive hydrodynamic pressure on tank wall and similarly on base. Liquid mass in the upper region of tank undergoes sloshing motion. This mass is termed as

\section{Volume 4 Issue 12, December 2015}




\section{International Journal of Science and Research (IJSR) \\ ISSN (Online): 2319-7064}

Index Copernicus Value (2013): 6.14 | Impact Factor (2014): 5.611

convective liquid mass and it exerts convective hydrodynamic pressure on tank wall and base.

Thus, total liquid mass gets divided into two parts, i.e., impulsive mass and convective mass. In spring mass model of tank-liquid system, these two liquid masses are to be suitably represented.

A qualitative description of impulsive and convective hydrodynamic pressure distribution on tank wall and base is given in Figure

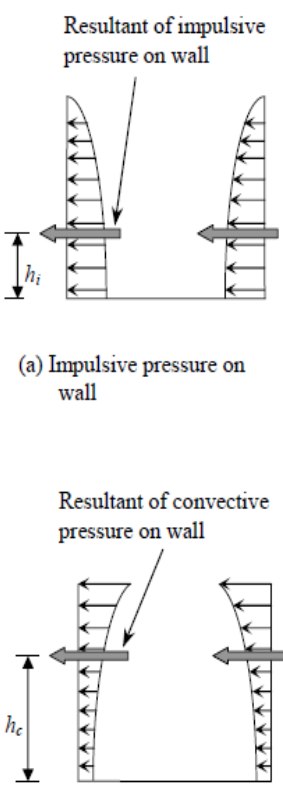

(c) Convective pressure on wall

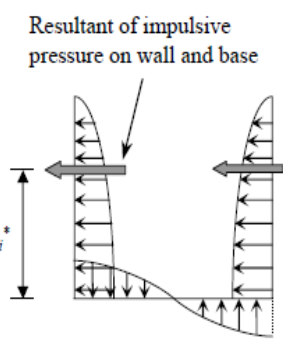

(b) Impulsive pressure on wall and base

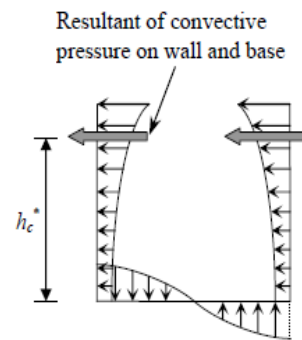

(d) Convective pressure on wall and base

\section{Description of Model}

Most elevated tanks are never completely filled with liquid. Hence a two-mass idealization of the tank is more appropriate as compared to a one mass idealization, which was used in IS 1893: 1984. Two mass model for elevated tank was proposed by Housner (1963b) and is being commonly used in most of the international codes.

Structural mass $m s$, includes mass of container and one-third mass of staging. Mass of container comprises of mass of roof slab, container wall, gallery, floor slab, and floor beams.

Staging acts like a lateral spring and one-third mass of staging is considered based on classical result on effect of spring mass on natural frequency of single degree of freedom system.

The response of the two-degree of freedom system can be obtained by elementary structural dynamics. However, for most elevated tanks it is observed that the two periods are well separated. Hence, the system may be considered as two uncoupled single degree of freedom systems. This method will be satisfactory for design purpose, if the ratio of the period of the two uncoupled systems exceeds 2.514. If impulsive and convective time periods are not well separated, then coupled 2-DOF system will have to be

solved using elementary structural dynamics. In this context it shall be noted that due to different damping of impulsive and convective components, this 2-DOF system will have non-proportional damping.

For elevated tanks [5], the two degree of freedom system of Figure c can be treated as two uncoupled single degree of freedom systems (Figure d), one representing the impulsive plus structural mass behaving as an inverted pendulum with lateral stiffness equal to that of the staging, Ks and the other representing the convective mass with a spring of stiffness, Kc. For tank shapes other than circular and rectangular (like intze, truncated conical shape), the value of $h / D$ shall correspond to that of an equivalent circular tank of same volume and diameter equal to diameter of tank at top level of liquid; and mi , mc , hi, hi*, hc , hc* and Kc of equivalent circular tank shall be used.

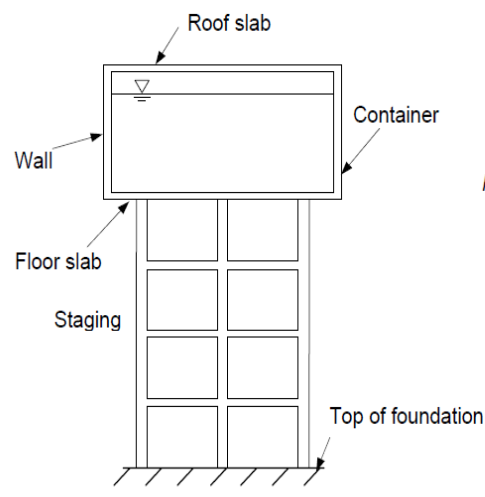

(a) Elevated tank

(c) Two mass idealization of elevated tank

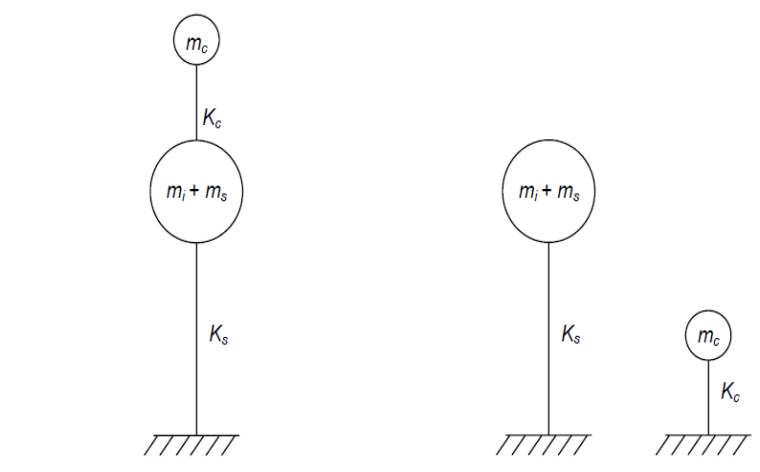

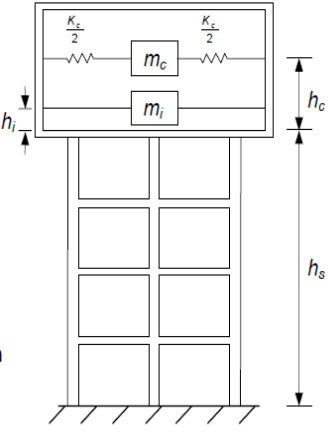

(b) Spring mass model a) Two Mass Idealization of Elevated Tank

For elevated tanks with moment resisting type frame staging, the lateral stiffness can be evaluated by computer analysis or by simple procedures (Sameer and Jain, 1992), or by established structural analysis method.

For elevated tanks with shaft type staging, in addition to the effect of flexural deformation, the effect of shear deformation may be included while calculating the lateral stiffness of staging.

Lateral stiffness of the staging is the horizontal force required to be applied at the centre of gravity of the tank to cause a corresponding unit horizontal displacement. The flexibility of bracing beam shall be considered in calculating the lateral stiffness, $K s$ of elevated moment resisting frame type tank staging. The important factors that affect the magnitude of earthquake forces are-

\section{Volume 4 Issue 12, December 2015}




\section{International Journal of Science and Research (IJSR) \\ ISSN (Online): 2319-7064}

Index Copernicus Value (2013): 6.14 | Impact Factor (2014): 5.611

b) Seismic zone factor, $Z$

India has been divided into four seismic zones as per IS 1893 (Part 1): 2002 for the Maximum Considered Earthquake (MCE) and service life of the structure in a zone. Different zone have different zone factor. Figure shows seismic zone map of India. India is divided into four seismic zones. There are three types of soil considered by IS 1893 (Part 1): 2002 i.e. soft medium and hard soil.

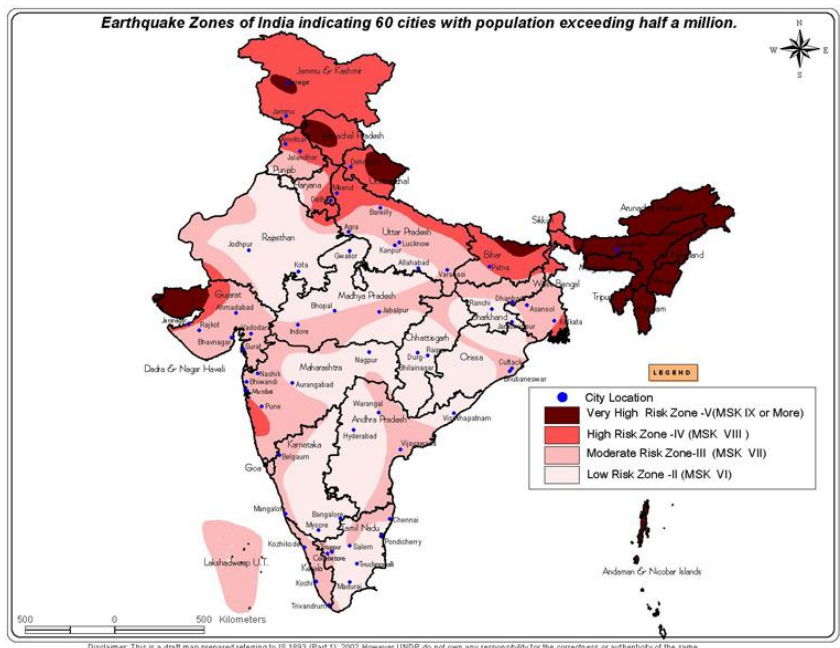

c) Importance factor, I

Importance factor depends upon the functional use of the structures, characterized by hazardous consequences of its failure, post-earthquake functional needs, historical value, or economic importance. Elevated water tanks are used for storing potable water and intended for emergency services such as fire fighting services and are of post earthquake importance. So importance factor is 1.5 for elevated water tank.

\section{d) Response reduction factor, $R$}

Response reduction factor depends on the perceived seismic damage performance of the structure, characterized by ductile or brittle deformations. $\mathrm{R}$ values of tanks are less than building since tanks are generally less ductile and have low redundancy as compared to building. For frame confirming to ductile detailing i.e. special moment resisting frame (SMRF), $\mathrm{R}$ value is 5 .

\section{e) Structural response factor, $(\mathrm{Sa} / \mathrm{g})$}

It is a factor denoting acceleration response spectrum of the structure subjected to earthquake ground vibrations, and depends on natural period of vibration and damping of the structure.

\section{Objective of the study}

The main objective of this study is to examine the Base shear of Elevated circular cylindrical water tank supported on frame staging considering different height and zone and plotting the graphs as base shear Vs height and base shear Vs zone.

\section{Method Used Calculating Base Shear}

STAAD.Pro.v8i is the most popular structural engineering software product for 3D model generation, analysis and multi-material design. It has an intuitive, user-friendly GUI, visualization tools, powerful analysis and design facilities and seamless integration to several other modelling and design software products. For static or dynamic analysis of bridges, containment structures, embedded structures (tunnels and culverts), pipe racks, steel, concrete, aluminium or timber buildings, transmission towers, stadiums or any other simple or complex structure, STAAD.Pro has been the choice of design professionals around the world for their specific analysis needs.

\section{Modelling of Water tank}

For this study, water tanks with five different heights such as $5 \mathrm{~m}, 10 \mathrm{~m}, 15 \mathrm{~m}, 20 \mathrm{~m}$ and $25 \mathrm{~m}$ are considered, and each water tank is placed in Zone 2, 3, 4, and 5. The effect of heights of tank and earthquake zones on base shear are observed with the help of analysis of 20 models having same parameters.

\section{Problem Description}

\section{Model 1}

An elevated, circular cylindrical shape water container of $500 \mathrm{~m}^{3}$ capacity is supported on RC staging of 8 columns with horizontal bracings of $225 \times 300 \mathrm{~mm}$ at four levels i.e. height of panel is equal to $3 \mathrm{~m}$. Staging conforms to ductile detailing as per IS 13920. Grade of concrete and steel are M25 and Fe415, respectively. Tank is located on hard soil in seismic zone II. Density of concrete is $25 \mathrm{kN} / \mathrm{m}^{2}$. The FEM structural software STAAD - PRO is used to model the elevated circular cylindrical water tank as shown in Fig. Columns and beams in the frame type support system are modelled as frame elements. Top domes, container walls and bottom slab of container are modelled with thin plate elements. Other dimensions of the elevated tanks are illustrated in Table.

\section{Parameters of Elevated Water Tank}

\begin{tabular}{|c|l|l|}
\hline S.N & Parameters & Values \\
\hline $\mathbf{( 1 )}$ & $\mathbf{( 2 )}$ & $\mathbf{( 3 )}$ \\
\hline 1 & Capacity of tank & $500 \mathrm{~m}^{3}$ \\
\hline 2 & Diameter of tank & $10 \mathrm{~m}$ \\
\hline 3 & Height of Cylindrical Wall & $5 \mathrm{~m}$ \\
\hline 4 & Thickness of Cylindrical Wall & $150 \mathrm{~mm}$ \\
\hline 5 & Height of staging & $12 \mathrm{~m}$ \\
\hline 6 & Height of Panel & $3 \mathrm{~m}$ \\
\hline 7 & Number of columns & 8 \\
\hline 8 & size of column & $450 \mathrm{~mm}$ dia. \\
\hline 9 & size of top ring beam & $150 \times 300 \mathrm{~mm}$ \\
\hline 10 & size of bottom ring beam & $450 \times 800 \mathrm{~mm}$ \\
\hline 11 & size of bracing & $225 \times 300 \mathrm{~mm}$ \\
\hline 12 & thickness of bottom slab & $225 \mathrm{~mm}$ \\
\hline 13 & thickness of dome & $75 \mathrm{~mm}$ \\
\hline 14 & density of concrete & $25 \mathrm{kN} / \mathrm{sq} \cdot \mathrm{m}$ \\
\hline 15 & Zone & IV $(0.24)$ \\
\hline 16 & Response reduction factor & $5(\mathrm{SMRF})$ \\
\hline 17 & Importance factor & 1.5 for water tank \\
\hline 18 & Type of soil & hard soil \\
\hline
\end{tabular}




\section{International Journal of Science and Research (IJSR) \\ ISSN (Online): 2319-7064}

Index Copernicus Value (2013): 6.14 | Impact Factor (2014): 5.611
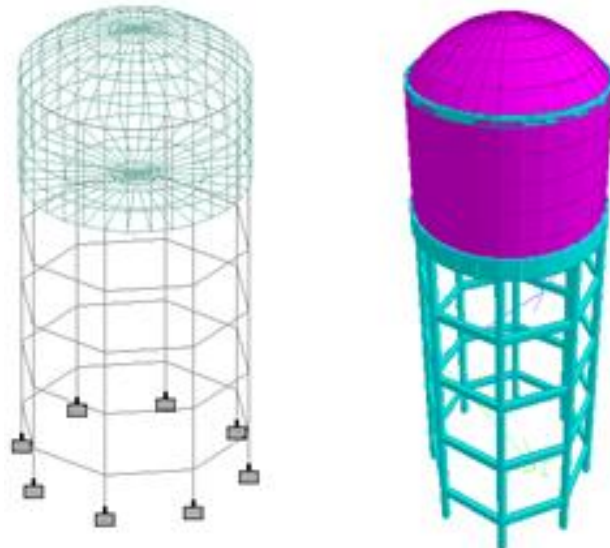

Typical cylindrical 3D View of cylindrical water tank water tank

Base Shear obtained from Staad-Pro Analysis

\begin{tabular}{|c|c|c|c|}
\hline Sr. No. & Tank Height & Zone & Base Shear(KN) \\
\hline 1 & $5 \mathrm{~m}$ & II & 197.528 \\
\hline & & III & 315.927 \\
\hline & & IV & 474.184 \\
\hline & & V & 711.569 \\
\hline 2 & $10 \mathrm{~m}$ & II & 295.078 \\
\hline & & III & 472.538 \\
\hline & & IV & 708.807 \\
\hline & & V & 1063.726 \\
\hline 3 & $15 \mathrm{~m}$ & II & 257.936 \\
\hline & & III & 413.729 \\
\hline & & IV & 620.077 \\
\hline & & V & 930.631 \\
\hline 4 & $20 \mathrm{~m}$ & II & 231.110 \\
\hline & & III & 369.363 \\
\hline & & IV & 554.045 \\
\hline & & V & 830.552 \\
\hline 5 & $25 \mathrm{~m}$ & II & 209.444 \\
\hline & & III & 334.284 \\
\hline & & IV & 501.427 \\
\hline & & V & 752.139 \\
\hline
\end{tabular}

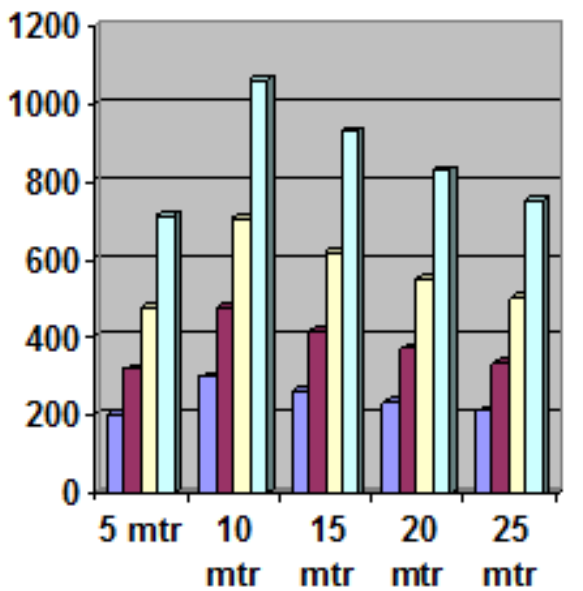

$\square$ Zone II $\square$ Zone III $\square$ Zone IV $\square$ Zone V

Graph 1: Base Shear Vs Height

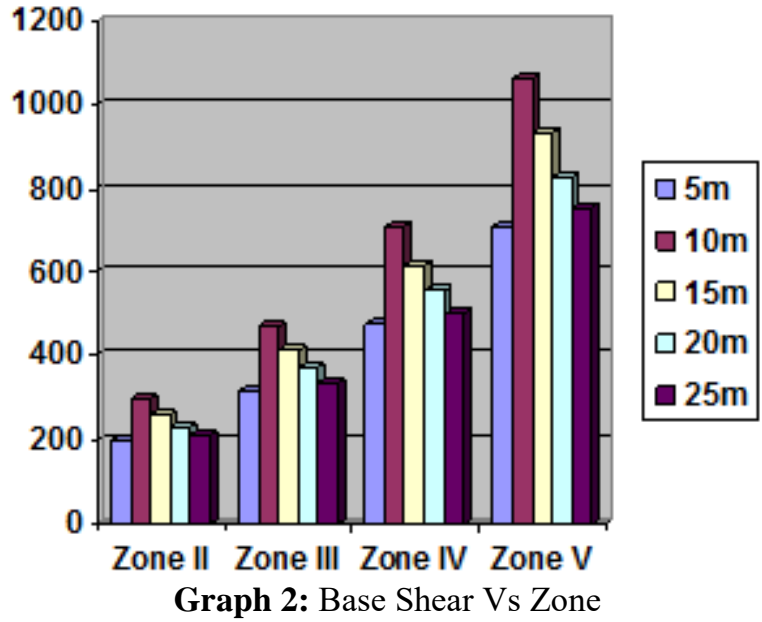

\section{Results and Discussions}

In this paper an attempt is made to study the seismic performance of the elevated water tanks. For all the above mentioned 20 water tanks, analysis has been carried out by using STAAD-PRO software. Earthquake analysis is carried out for different heights and different earthquake zones. The main objective of this paper was to study the effect on seismic forces on reinforced cement concrete elevated water tank in seismic zones II, III, IV and V for different heights of the elevated water tank.

\section{Effect of height of water tank on Base Shear}

The results obtained from analysis are analyzed and shown in graphical form. Graph 1 shows the effect of varying height of tank on base shear by considering zone II, III, IV, $\mathrm{V}$ for particular height i.e. it shows that by increasing height of tank, Base shear is at its peak for $10 \mathrm{~m}$ height and again goes down from $10-25 \mathrm{~m}$ for each particular earthquake zone. And if we consider particular $5 \mathrm{~m}$ as height of tank then Base Shear successively increases from Zone II to Zone $\mathrm{V}$.

\section{Effect of earthquake zone on Base Shear}

Graph 2 shows the effect of earthquake zones on Base shear by considering heights of water tank $5 \mathrm{~m}, 10 \mathrm{~m}, 15 \mathrm{~m}, 20 \mathrm{~m}$, $25 \mathrm{~m}$ for particular zone. From this graph it is observed that by varying zone, Base shear successively increases from zone II to $\mathrm{V}$.

And if we consider Particular Zone II, Base Shear increases up to $10 \mathrm{~m}$ and then decreases from $10 \mathrm{~m}$ to $25 \mathrm{~m}$ height of tank.

\section{Conclusion}

1) Design of water tank is a very tedious method. Particularly design of elevated cylindrical water tank involves lots of mathematical formulae and calculation. It is also time consuming. Hence Staad - pro gives a base shear value from the analysis immediately.

2) Base Shear increases from zone II to Zone V keeping all parameters of water tank constant height also.

3) Base shear is at its peak for $10 \mathrm{~m}$ height and again goes down from 10-25 m keeping all parameters of water tank constant zone.

\section{Volume 4 Issue 12, December 2015}




\section{International Journal of Science and Research (IJSR) \\ ISSN (Online): 2319-7064}

Index Copernicus Value (2013): 6.14 | Impact Factor (2014): 5.611

4) Present study will be useful to Civil Engineers to understand the behaviour of elevated water tank for various heights and also to get the feel of effect of earthquake zones of India on earthquake forces.

\section{References}

[1] Gaikwad, M.V. (2013). "Comparison between static and dynamic analysis of elevated water tank". International Journal of Civil Engineering and Technology, 4(3), 2043-2052.

[2] Gaikwad, M.V.(2013)."Seismic performance of Circular Elevated Water Tank with Framed Staging". International Journal of advanced research in Engineering and Technology, 4(4), 159-167.

[3] Hirde, S., Bajare, A. and Hedaoo, M. (2011). "Seismic performance of elevated water tanks". International Journal of Advanced Engineering Research and Studies, 1(1), 78-87.

[4] IITK-GSDMA (2007). "Guidelines for seismic design of liquid storage tanks", National Information Centre for Earthquake Engineering, IIT Kanpur.

[5] IS:1893(Part-2)-2002. “Criteria for Earthquake Resistant Design of Structures Part 2 Liquid Retaining Tanks", Bureau of Indian Standards, New Delhi.

[6] Ekbote, S.P. (2013). "Seismic behaviour of RC elevated water tank under different types of staging pattern". Journal of Engineering, Computers \& Applied Sciences, 2(8), 23-29.

[7] Krishna Rao M.V, Rathish Kumar. P, Divya Dhatri. K. (2015) "Seismic Analysis of Overhead Circular Water Tanks- A Comparative study". International Journal of Research in Engineering and Technology, 4(1), 74-83.

[8] D. D. Bachhav, G.R. Patil (2015). "Behaviour of Elevated Water Tank on Shaft Type of Staging Subjected to Seismic Loading." International Journal of Informative and Futuristic Research, 3(1), 177-193.

[9] G.P.Deshmukh, Ankush.S.Patekhede, "Analysis of Elevated Water Storage Structure Using Different Staging System". International Journal of Research in Engineering and Technology, 4(4), 283-287. 